\title{
Thinking Climate - A Mind Genomics Cartography
}

\author{
Howard Moskowitz ${ }^{1 *}$, Avi Yaschin ${ }^{2}$, Ariola Harizi ${ }^{3}$, Sophia Davidov ${ }^{4}$, Pnina Deitel ${ }^{5}$ and Attila Gere ${ }^{6}$ \\ ${ }^{1}$ MindCart AI New York, USA \\ ${ }^{2}$ Independent Researcher, New York, USA \\ ${ }^{3}$ Slovak University of Agriculture, Nitra, Slovakia \\ ${ }^{4}$ Independent Researcher, Toronto, Canada \\ ${ }^{5}$ The Open University, Jerusalem, Israel \\ ${ }^{6}$ Szent István University, Budapest, Hungary
}

*Corresponding author: Howard Moskowitz, MindCart AI New York, USA

Received: December 16, 2020; Accepted: December 21, 2020; Published: December 23, 2020

\begin{abstract}
The paper deals with the inner mind of the respondent about climate change, using Mind Genomics. Respondents evaluated different combinations of messages about problems and solutions touching on current and future climate change. Respondents rated each combination on a two-dimensional scale regarding believability and workability. The ratings were deconstructed into the linkage between each message and believability vs. workability, respectively. Two mind-sets emerged, Alarmists who focus on the problems that are obvious to climate change, and Investors who focus on a limited number of feasible solutions. These two mind-sets distribute across the population, but can be uncovered through a PVI, personal mind-set identifier.
\end{abstract}

\section{Introduction}

\section{Importance of the Weather and Climate}

As of this writing, the concerns about climate i daily in written materials, whether the news or in academic articles. A search during mid-December 2020 reveal 416 million hits for 'global warming,' 350 million hits for 'global cooling' 886 million his for 'weather storms' and 608 million hits for 'global weather change.' The academic literature shows the parallel level of interest in weather and its changes. A retrospective of issues about climate change shows the increasing number of 'hit' over the past 20 years, as Table 1 shows. These hits suggest that issues regarding climate change are high on the list of people's concerns.

\section{Beyond Surveys to the Inside of the Mind}

The typical news story about climate changes is predicated on storytelling, combining a historical overview, current economic

Table 1a: Number of 'hits' on Google Scholar for different aspects of climate change.

\begin{tabular}{|c|c|c|c|c|}
\hline Year & $\begin{array}{c}\text { Global } \\
\text { Warming }\end{array}$ & $\begin{array}{c}\text { Global } \\
\text { Cooling }\end{array}$ & Weather Storms & $\begin{array}{c}\text { Global Weather } \\
\text { Change }\end{array}$ \\
\hline 2000 & 14,900 & 22,300 & 8,370 & 34,300 \\
\hline 2002 & 30,900 & 111,900 & 10,400 & 61,500 \\
\hline 2004 & 39,900 & 126,00 & 13,100 & 75,300 \\
\hline 2006 & 52,200 & 129,000 & 14,600 & 92,300 \\
\hline 2008 & 82,200 & 132,000 & 19,600 & 111,000 \\
\hline 2010 & 105,000 & 153,000 & 23,700 & 128,000 \\
\hline 2012 & 112,000 & 154,000 & 26,700 & 137,000 \\
\hline 2014 & 109,000 & 154,000 & 28,200 & 136,000 \\
\hline 2016 & 96,300 & 131,000 & 27,900 & 114,000 \\
\hline 2018 & 77,900 & 85,200 & 27,400 & 81,200 \\
\hline
\end{tabular}

Table 1b: The four questions and the four answers to each question

\begin{tabular}{|l|l|}
\hline & Question A: What climate impacts do people see today? \\
\hline A1 & Sea Levels are rising and flooding is more frequent \& obvious \\
\hline A2 & Hurricanes are getting stronger and more frequent - just look at the news \\
\hline A3 & Heat Waves are damaging crops and the food supply \\
\hline A4 & Wildfires are more massive and keep burning down neighborhoods \\
\hline & Question B: What are the underlying risks in 20 years? \\
\hline B1 & Coastal property investments lose money \\
\hline B2 & Children will live in a much lousier world \\
\hline B3 & Governments will start being destabilized \\
\hline B4 & People will turn from optimistic to pessimistic \\
\hline & Question C: What are some actions we can take to avoid these problems? \\
\hline C1 & Right now, implement a global carbon tax \\
\hline C2 & Over time, transfer $10 \%$ of global wealth to an environment fund \\
\hline C3 & Create a unified global climate technology consortium for technological change. \\
\hline C4 & Build a solar shade that blocks $2 \%$ of sunlight \\
\hline & $\begin{array}{l}\text { Question D: What's the general nature of the system that will mitigate these } \\
\text { risks today? }\end{array}$ \\
\hline D1 & \$10trn to move all energy generation to carbon neutral \\
\hline D2 & \$20trn to harden the grid and coastal communities \\
\hline D3 & \$2trn to build a space based sunshade blocking $2 \%$ of sunlight. \\
\hline D4 & \$0.02trn to spray particulate into atmosphere to block $2 \%$ of sunlight. \\
\hline
\end{tabular}

concerns, description of behavior from a social psychology or sociological viewpoint, and often a doom and gloom prediction which demands action today to be forestalled. All aspects are correct, in theory. What is missing is a deeper understanding of the inner thinking of a person when confronting the issue of climate change. 
There are some papers which do deal with the 'mind' of the consumer, usually from the point of view of social psychology, rather than experimental psychology [1].

Most conversations about climate change are general, because of the lack of specific knowledge, and the inability of people to deal with the topic in depth. The topic of climate change and the potential upheavals remains important, but people tend to react in an emotional way, often accepting everything or rejecting what sounds reasonable or what does not sound reasonable, respectively. The result is the ongoing lack of specific information, compounding the growth of anxiety, and the increasingly strident rejectionism by those who fail to respond to what is believed to be an impending catastrophe. Another result, just as inaction, is a deep, perplexing, often consuming discourse on the problem, written in way which demonstrates scholarship and rhetorical proficiency, but does not lead to insights or answers, rather to well justified polemics [2-6]. The study reported here, a Mind Genomics 'cartography' delves into the mind of the average person, to determine what specifics of climate change are believable, what solutions are deemed to be workable, and what elements or messages about climate change engage a person's attention. The objective is to understand the response to the notion of climate change by focusing of reactions to specifics about climate change, specifics presented to the respondent in the form of small combinations of 'facts' about climate [7-9].

Researchers studying how people think about climate follow two approaches, the first being the qualitative approach which is a guided, but free-flowing interview or discussion, the second being a structured questionnaire. The traditional qualitative approach requires the respondent to talk in a group about feelings towards specifics, or even talk an in in-depth, 1:1 interview. These are the accepted methods to explore thinking, so-called focus groups and indepth interviews. Traditional discussion puts stress on the respondent to recall and state, to produce and to recite in the language of the experimental psychologist. In contrast, the traditional survey presents the respondent with a topic, and asks a variety of questions, to which the respondent selects the appropriate answer, either by choice, or by providing the information. All in all, conventional research gives a sense of the idea, but form the outside in. Reading a book written by researchers about a topic will provide the outside, and illustrative comments from individuals to highlight the point. Yet, it will be clearly from the outside, rather than a sense of peering out from the inside of the mind. The qualitative methods may reach into the mind somewhat more deeply because the respondent is asked to talk about a topic and must 'produce' information from inside. Both the qualitative and the quantitative methods produce valuable information, but information of a general nature. The insights which may emerge from the qualitative and quantitative methods have a sense of emerging from the 'outside-in.' That is, there is insight, but there is not the depth of specific material relevant to the topic, since the qualitative information is in the form of diluted ideas, ideas diluted in a discussion, whereas the quantitative information is structured description with a sense of deep specificity.

\section{The Contribution of Mind Genomics}

Mind Genomics is an emerging science, with origins in experimental psychology, consumer research, and statistics. The foundational notion of Mind Genomics is that we can uncover the ways that people make decisions about every-day topics using simple experiments, where people respond to combinations of messages abut the different aspects of the topic. These combinations, created by experimental design, present information to the respondent in a rapid fashion, requiring the respondent to make a quick judgment. The mixture of different messages in a hard-to-disentangle fashion, using experimental design, makes it both impossible to 'game' the system, and straightforward to identify which pieces of information drive the judgment. Furthermore, one can discover mind-sets of individuals quite easily, groups of people with similar pattern of what they deem to be important. The approach here, Mind Genomics, makes the respondents job easier, to recognize and react. The messages are shown to the respondent in combinations, the respondents evaluate the combination, and the analysis identifies which messages are critical, viz, which messages about weather change are important. Mind Genomics approaches the problem by combining messages about a topic, messages which are specific. Thus, Mind Genomics combines the richness of ideas obtained from qualitative research with the statistical rigor of quantitative research found in surveys. Beyond that combination, Mind Genomics is grounded in the world of experiment, allowing the researcher to easily understand the linkage between the qualitatively, rich, nuanced information, presented in the experiment, and the reaction of the respondent, doing so in a manner which cannot be 'gamed' by the respondent, in a manner which reveals both cognitive responses (agree/disagree) and non-cognitive response (engagement with the information as measured by response time.)

Mind Genomics follows a straightforward path to understand the way people think about the everyday. Mind Genomics is fast (hours), inexpensive, iterative, and data-intensive, allowing for rapid, upfront analysis and deeper post-study analysis. Mind Genomics has been crafted with the vision of a system which would allow anyone to understand the mind of people, even without technical training. The grand vision of Mind Genomics is to create a science of the mind, a science available to everyone in the world, easy-to-do, a science which creates a 'wiki of the mind', a living database of how people think about all sorts of topics.

\section{Doing a Simple Cartography - The Steps}

\section{Step 1 - Create the Raw Materials; Topic, Four Questions, Four Answers to Each Question}

The cartography process begins with the selection of a topic, here the mind of people with respect to climate change. The topic is only a tool by which to focus the researcher's mind on the bigger areas.

Following the selection of the topic, the researcher is requested to think of four questions which are relevant to the topic. The creation of these questions may sound straightforward, but it is here that the respondent must exercise some creative and critical thinking, to identify a sequence of questions which 'tell a story.' The reality is 
that it takes about 2-3 small experiments, the cartographies, before the researcher 'gets it,' but once the researcher understands how to craft the questions relative to the topic, the researcher's critical faculty and thinking patterns have forever changed. The process endows the researcher with in a new, powerful, simultaneous an analytic and a synthetic way of thinking. Once the four questions are decided upon, the researcher's next task is to come up with four answers. The perennial issue now arises regarding 'how do I know I have the right or correct answers?' The simple answer is one does not. One simply does the experiment, finds out 'what works', and proceeds with the next step of stimuli. After two, three, four, even five or six iterations, each taking 90 minutes, it is likely that one has learned what works and what does not. The iteration consists of eliminating ideas or directions which do not work, trying more of the type of ideas which do work, as well as other exploring other but related directions with other types of ideas.

It is important to emphasize the radically different thinking behind Mind Genomics, which is meant to be fast and iterative, and not merely to rubber stamp or confirm one's thinking. Speed and iteration lead to a wider form of knowledge, a sense of the boundaries of a topic. In contrast, the more conventional and focused thinking lead to rejection or confirmation, but little real learning.

\section{Step 2 - Combine the Elements into Small Vignettes that will be Evaluated by the Respondents}

The typical approach to evaluation would be to present each of the elements in Table 1 to the respondent, one element at a time, instructing the respondent to rate the element alone, using a scale. Although the approach of isolate and measure is appropriate in science, the approach carries with it the potential of false results, based upon the desire of most respondents to give the 'right answer.'

Mind Genomics works according to an entirely different principle. Mind Genomics presents the answers or elements in what appear to be random combinations, but nothing could be further from the truth. The combinations are well designed, presenting different types of information. It will be the rating of the combination, and then the deconstruction of that rating into the contributions of the 16 individual elements which reveal the mind of the respondent. The experimental design simply ensures that the elements are thrown together in a known but apparently haphazard way, forcing the respondent to rely on intuitive or 'gut responses', the type judgment which governs most of everyday life. Nobel Laureate Daniel Kahneman calls this 'System 1' Thinking, the automatic evaluation of information in an almost subconscious but consistent and practical manner [10].

The underlying experimental design used by Mind Genomics requires each respondent to evaluate 24 different vignettes, or combinations, with a vignette comprising 2-4 elements. Only one element or answer to a question can appear in a single vignette, ensuring that a vignette does not present elements which directly contradict each other, viz., by comprising two elements from the question or silo, presenting two alternative and contradictory answers to the question. The experimental design might be considered as a form of advanced bookkeeping [11].
Many researchers feel strongly that every vignette must have exactly one element or answer from each question. Their point of view is that otherwise the vignettes are not 'balanced', viz., some vignettes have more information, some vignettes have less information. Their point of view is acceptable, but by having incomplete vignettes, the underlying statistics, OLS (ordinary least-squares) regression cannot estimate absolute values for coefficients. By forcing each vignette to comprise exactly one element or answer from each question, the OLS regression will not work because the system is 'multi-collinear.' The coefficients can only be estimated in a relative sense, and not comparable across questions for the study, nor comparable across studies in the same topic, and of course not comparable for different topics. That lack of comparability defeats the ultimate vision of Mind Genomics, viz., to create a 'wiki of the mind.' A further point regarding the underlying experimental design is that Mind Genomics explores a great deal of the design space, rather than testing the same 24 vignettes with each respondent. Covering the design space means giving up precision obtained by reducing variability through averaging, the strategy followed by most researchers who replicate or repeat the study dozens of times, with the vignettes in different orders, but nonetheless with the same vignettes. The underlying rationale is to average out the noise, albeit at the expense of testing a limited number of vignettes again and again.

\section{Step 3 - Select an Introduction to the Topic and a Rating Scale}

The introduction to the topic appears below. The introduction is minimal, setting up as few expectations as possible. It will the job of the elements to convey the information.

Please read the sentences as a single idea about our climate. Please tell us how you feel.

1) No way.

2) Don't believe, and this won't work.

3) Believe, but this won't work.

4) Don't really believe, but this will work.

5) I believe, and this will work.

The scale for this study is anchored at all five points, rather than at the lowest and at the highest point. The scale deals with both belief in that which is written, and belief that the strategy will work. The respondent is required to select one scale point out of the five for each vignette, respectively. The scale allows the researcher to capture both belief in the facts and belief in the solutions.

\section{Step 4 - Invite Respondents to Participate}

The respondents are invited to participate by an email. The respondents are member of Luc.id, an aggregator of online panels, with over 50 million panelists. Luc.id, located in Louisiana, in the United States, allows the researcher to tailor the specifications of the respondents. No specifics other than US respondents were imposed on the panel. The respondents began with a short self-profiling classification questionnaire, regarding age and gender, as well as the answer to the question below: 
How involved are you in thinking about the future?

$1=$ Worried about my personal situation with my family

$2=$ Worried about business stability

$3=$ Worried about climate and ecological stability

$4=$ Worried about government stability.

The respondent then proceeded to rate the 24 unique combinations from the permuted experimental design, with the typical time for each vignette lasting about 5-6 seconds, including the actual appearance time, and the wait time before the next appearance [12]. The actual experiment thus lasted 2-3 minutes.

\section{Step 6 - Acquire the Ratings and Transform the Data in Preparation for Model}

In the typical project the focus of interest is on the responses to the specific test stimuli, whether there be a limited number of test vignettes (viz., not systematically permuted, but rather fixed), or answers to a fixed set of questions. The order of the stimuli or the test questions might be varied but there a fixed, limited number. With Mind Genomics the focus will be on the contribution of the elements to the responses. Typically, the responses are transformed from a scale of magnitude (e.g., 1-5, not interested to interested), so that the data are binary (viz., 1-3 transformed to 100 to show that the respondents are not interested; $4-5$ transformed to -100 to show that the respondent is interested.

As noted above, there are two scales intertwined, a belief in the proposition, and a belief that the action proposed will work. The two scales generate two new binary variables are created, rather than one binary variable:

Believe: Ratings of 1,2, 4 converted to 0 (do not believe the statements), ratings of 3,5 converted to 100 (believe the statements

Work (Efficacious) Ratings of 1,2,3 converted to 0 (do not believe the solution will work), ratings 4,5 converted to 100 (believe the proposed solution will work).

In these rapid evaluations we do not expect the respondent to stop and think. Rather, it turns out that 'Believe' is simply 'does it sound true, ' and 'Work' is simply 'does seem to propel people to solve the problem. Both of these are emotional responses. The end-product is a matrix of 24 rows for each respondent, one row for each vignette tested by that respondent. The matrix comprises 16 columns, one column for each of the 16 elements. The cell for a particular row (vignette) and for a particular column (element) is either 0 (element absent from that vignette) or 1 (element present in that vignette). The last four columns of the matrix are the rating (1-5), the response time (in seconds, to the nearest $10^{\text {th }}$ of a second), and the two new binary values for the scales 'Believe' and 'Work' respectively (0 for not believe or not work, 100 for believe or work, depending upon the rating, plus a small random number $<10^{-5}$ ).

Step 7 - Create Two Models (Equations) for Each Respondent, a Model for Believe, and a Model for Work, and then Cluster

\section{the Respondents Twice, First for the Individual 'Believe' Models, Second for the Individual 'Work' Models}

The experimental design underlying the creation of the 24 vignettes for each respondent allows us to create an equation at the respondent level for Believe (Binary) $=\mathrm{k}_{0}+\mathrm{k}_{1}(\mathrm{~A} 1)+\mathrm{k}_{2}(\mathrm{~A} 2) \ldots .+$ $\mathrm{k}_{16}(\mathrm{D} 4)$. The dependent variable is either 0 or 100 , depending upon the value of the specific rating in Step 6. The small random number added to each binary transformed number ensures that there is variation in the dependent variable.

1. Believe Models. For the variable Believe, applying OLS regression generates the 16 coefficients $\left(k_{1}-k_{16}\right)$ and the additive constant, for each of the 55 respondents. A clustering algorithm (k-means, distance $=1=$ Pearson Correlation) divides the respondents into two groups. We selected the two groups (called mind-sets) because the meanings of the two groups were clear. Each respondent was then assigned to one of the two emergent groups, viz., mind-sets, based on the respondent's coefficients for Believe as a dependent variable [13].

2. Work Models. A totally separate analysis was done, following the same process, but this time using the transformed variable 'Work'. The respondents were then assigned to one of the two newly developed mind-sets, based only on the coefficient for work.

As a rule of thumb, one can extract many different sets of complementary clusters (mind-sets), but a good practice is to keep the number of such selected sets to a minimum, the minimum based upon the interpretability of the mind-sets. In the interests of parsimony, one should stop as soon as the mind-sets make clear sense.

\section{Step 8 - Create Group Equations; Three Models or Equations,} One for Believe, One for Work, One for Response Time

Create these sets of three models each for Total Panel, Male, Female, Younger (age 18-39), Older (age 40+), and the mind-sets. The equations are similar in format, but not identical:

$$
\begin{aligned}
& \text { Believe }=k_{0}+k_{1}(A 1)+k_{2}(A 2) \ldots k_{16}(D 4) \\
& \text { Work }=k_{0}+k_{1}(A 1)+k_{2}(A 2) \ldots k_{16}(D 4) \\
& \text { Response Time }=k_{1}(A 1)+k_{2}(A 2) \ldots k_{16}(D 4)
\end{aligned}
$$

For the mind-sets, create two models only.

Mind-Set based on 'believe':

$$
\begin{aligned}
& \text { Believe }=k_{0}+k_{1}(A 1)+k_{2}(A 2) \ldots k_{16}(D 4) \\
& \text { Response Time }=k_{1}(A 1)+k_{2}(A 2) \ldots k_{16}(D 4) \\
& \text { Mind-set based on 'work' } \\
& \text { Work } \left.=k_{0}+k_{1}(A 1)+k_{2}(A 2) \ldots k_{16}(D 4)\right) \\
& \text { Response Time }=k_{1}(A 1)+k_{2}(A 2) \ldots k_{16}(D 4) .
\end{aligned}
$$




\section{Results}

\section{External Analysis}

The external analysis looks at the ratings, independent of the nature of the vignettes, either structure or composition of the vignette in terms of specific elements. We focus here on a topic which is deeply emotion to some. The first analysis that we will focuses on the stability of the data for this deeply emotional topic. As noted above, the Mind Genomics process requires the respondent to evaluate a unique set of 24 vignettes. Are the ratings stable over time or is there so much random variability that by the time the respondent has completed the study the respondent is not paying any more attention, and simply pressing the rating button. We cannot plot the rating of the same vignette across the different positions for the same reason that each respondent tested a totally unique set of combinations. We can track the average rating, the average response time, and then the standard errors of both, across the 24 positions. If the respondent somehow stops paying attention, then the rating should show less variation over time.

Figure 1 shows the averages and standard errors for the two measures, the ratings actively assigned by the respondent, and the response time, not directly a product of the respondent's 'judgment,' but rather a measure of the time taken to respond. The abscissa shows the order in the set, from 1 to 24 , and the ordinate shows the statistic. The data show that the response time is longer for the first few vignettes (viz., test order 1-3), but then stabilizes. The data further show that for the most part, the ratings themselves are stable, although there are effects at the start and at the end. Figure 1 suggests remarkable stability, a stability that has been observed for almost all Mind Genomics studies, when the respondents are members of an on-line panel, and remunerated by the panel provided for their participation.
The second external analysis shows the distribution of ratings by key subgroups across all of the vignettes evaluated by each key subgroup. For each key subgroup (rows), Table 2 shows the distribution of the five scale points (A), distribution of the two scale points $(3,5)$ points which reflect belief $(3,5)$ distribution of the two scale points

Table 2: Distribution of ratings on Net Believe Yes, and Net Work YES five-point scale, by key groups, and by key clusters of scale points.

\begin{tabular}{|l|c|c|}
\hline & $\begin{array}{c}\text { Net Believe YES } \\
\text { (\% Rating 3 or 5) }\end{array}$ & $\begin{array}{c}\text { Net Work YES (\% } \\
\text { Rating 4 or 5) }\end{array}$ \\
\hline Total & 45 & 44 \\
\hline Vignettes 1-12 & 43 & 43 \\
\hline Vignettes 13-24 & 47 & 45 \\
\hline Male & 46 & 52 \\
\hline Female & 44 & 36 \\
\hline Age 24x-9 & 47 & 49 \\
\hline Age 40+ & 43 & 38 \\
\hline Worry business & 43 & 31 \\
\hline Worry about climate & 50 & 52 \\
\hline Worry about family & 45 & 48 \\
\hline Worry about government & 43 & 39 \\
\hline Worry about 'outside' (business + climate) & 43 & 35 \\
\hline Worry about 'inside' (family + government) & 46 & 49 \\
\hline Belief - MS1 & 44 & 48 \\
\hline Belief MS2 & 47 & 40 \\
\hline Work - MS 3 & 46 & 49 \\
\hline Work - MS4 & 44 & \\
\hline Response Time - MS5 & & 39 \\
\hline Response Time - MS6 & 46 & \\
\hline
\end{tabular}

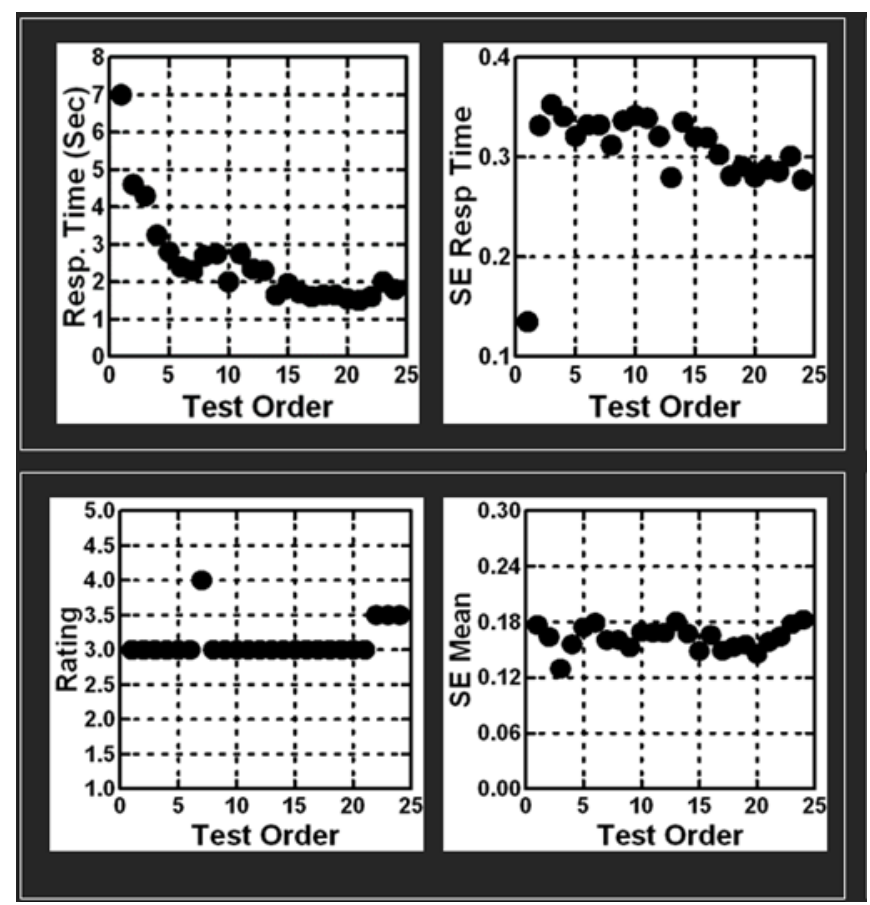

Figure 1: The relation between test order (abscissa) and key measures. The top panel shows the analysis of the response times (mean RT on left, standard error of the mean on the right). The bottom panel shows the analysis of the ratings (mean rating on the left, standard error of the mean on the right). 
$(4,5)$ reflecting positive feeling that the idea 'works' The patterns of ratings suggest that a little fewer than half the responses are believe or work. However, we do not know the specific details about which types of messages drive these positive responses. We need a different level of inquiry, an internal analysis into what patterns of elements drive the responses.

\section{Internal Analysis - What Specific Elements Drive with or Link with 'Believe' and 'Work' Respectively}

Up to now we have considered only the surface aspect of the data, namely the reliability of the data across test order (Figure 1), and the distribution of the ratings by key subgroup (Table 2). There is no sense of the inner mind of the respondent, about what elements link with believability of the facts, with agreement that the solution will work, or how deeply the respondent engages in the processing of the message, as suggested by response time. The deeper knowledge comes from OLS (ordinary least squares) regression analysis, which relates the presence/absence of the 16 messages to the ratings, as explicated in Step 8 above.

Table 3 shows the first table of results, the elements which drive 'believability.' Recall from the methods section that the 5-point scale had two points with the respondent 'believing, and that these ratings $(3,5)$ generated a rating of 100 for the scale of 'believe', whereas the other three rating points $(1,2,4)$ were converted to 0 . The self-profiling classification also provides the means to assign a respondent based upon what the respondent said was most concerning, worry about self (family, government), worry about other/outside (business, climate). Table 3 shows the additive constant, and the coefficients for each group. Only the Total Panel shows coefficients which are 0 or negative. The other groups show only coefficients which are positive. Furthermore, the table is sorted by the magnitude of the coefficient for the Total
Panel. In this way, one need only focus on those elements which drive 'belief', viz., elements which demonstrate a positive coefficient. Elements which have a 0 negative coefficient are those which have no impact on believability. They may even militate against believability. Our focus is strictly what drives a person to say 'I believe what I am reading.'

We begin with the additive constant across all of the key groups in Table 3. The additive constants tell us the likelihood that a person will rate a vignette as 'I believe it' in the absence of elements. The additive constant is a purely estimated parameter, the 'intercept' in the language of statistics. All vignettes comprised 2-4 elements by the underlying experimental design. Nonetheless, the additive constant provides a good sense of basic proclivity to believe in the absence of elements. The additive constants hover between 40 and 50 with two small exceptions of 37 and 53 . The additive constant tells us that the respondent is prepared to believe, but only somewhat. In operational terms, an additive constant of 45 , for example, means that out of the next 100 ratings for vignettes, 45 will be ratings corresponding to 'believe,' viz., selection of rating points 3 or 5 , respectively. The story of what makes a person believe lies in the meaning of the elements. Elements whose coefficient value is +8 or higher are strongly 'significant' in the world of inferential statistics, based upon the 'T test' versus a coefficient with value 0 . There are only a few of these elements which drive strong belief.

The most noteworthy finding is that respondents in Q3 Inside (worried about issues close to them) start out with a high propensity to believe (additive constant $=53$ ), but then show ability to differentiation among the elements. They do not believe anything. In contrast, respondents who say they worry about issues outside of them start with low belief (additive constant 53), but there are a several of elements which strongly drive their belief (e.g., A4: Wild-Fires are more massive

Table 3: Elements which drive 'belief'. Only positive coefficients are shown. Strong performing elements are shown in shaded cells.

\begin{tabular}{|c|c|c|c|c|c|c|c|c|}
\hline & Ratings of Believe (Scale values 3,5 $\rightarrow 100$ ) & Total & Male & Female & Age 18-39 & Age 40+ & Q3 Inside & Q3 Outside \\
\hline & Additive constant & 47 & 50 & 44 & 47 & 47 & 53 & 37 \\
\hline D1 & $\$ 10$ trn to move all energy generation to carbon neutral & 3 & & & 10 & 7 & & 3 \\
\hline A3 & Heat Waves are damaging crops and the food supply & 2 & & 6 & 2 & 3 & & 5 \\
\hline B3 & Governments will start being destabilized & 2 & & 7 & & 3 & & 6 \\
\hline D2 & $\$ 20$ trn, to harden the grid and coastal communities & 2 & 1 & 3 & 6 & & 4 & \\
\hline A2 & Hurricanes are getting stronger and more frequent - just look at the news & 1 & & 5 & 3 & & & 7 \\
\hline A4 & Wild-Fires are more massive and keep burning down neighbourhoodS & 1 & & 2 & 2 & 1 & & 9 \\
\hline D3 & $\$ 2 \operatorname{trn}$ to build a space based sun shade, blocking $2 \%$ of sunlight. & 1 & 2 & & 1 & & & 10 \\
\hline D4 & $\$ 0.02$ trn to spray particulate into atmosphere to block $2 \%$ of sunlight. & 1 & & & 8 & 6 & & 6 \\
\hline A1 & Sea Levels are rising and flooding is more frequent \& obvious & -1 & & & 3 & & & \\
\hline B2 & Children will live in a much lousier world & -1 & & & 8 & & & \\
\hline $\mathrm{C} 2$ & Over time, transfer $10 \%$ of global wealth to an environment fund & -1 & 2 & & & 2 & & \\
\hline $\mathrm{C} 3$ & Create a unified global climate technology consortium for technological change. & -2 & & & & 4 & & \\
\hline B1 & Coastal property investments lose money & -3 & & & & & & \\
\hline B4 & People will turn from optimistic to pessimistic & -3 & & 1 & & & & 2 \\
\hline $\mathrm{C} 1$ & Right now .. implement a global carbon tax & -4 & & & & 3 & & \\
\hline $\mathrm{C} 4$ & Build a solar shade that blocks $2 \%$ of sunlight & -5 & 0 & & & & & 3 \\
\hline
\end{tabular}


Table 4: Elements which drive 'work'. Only positive coefficients are shown. Strong performing elements are shown in shaded cells.

\begin{tabular}{|c|c|c|c|c|c|c|c|c|}
\hline & Ratings of Work- (Scale Values $4,5 \rightarrow 100$ & Total & Male & Female & Age 18-39 & Age 40+ & Q3 Inside & Q3 Outside \\
\hline & Additive constant & 43 & 52 & 36 & 50 & 35 & 49 & 36 \\
\hline $\mathrm{C} 4$ & Build a solar shade that blocks $2 \%$ of sunlight & 5 & 3 & 7 & 6 & 4 & 5 & 7 \\
\hline B4 & People will turn from optimistic to pessimistic & 2 & 2 & 2 & 4 & & 3 & \\
\hline $\mathrm{C} 1$ & Right now... implement a global carbon tax & 2 & & 4 & 1 & 2 & 3 & \\
\hline C3 & Create a unified global climate technology consortium for technological change. & 2 & 1 & 2 & & 3 & 2 & 1 \\
\hline D4 & $\$ 0.02 \operatorname{trn}$ to spray particulate into atmosphere to block $2 \%$ of sunlight. & 2 & 8 & & & 10 & 3 & 1 \\
\hline $\mathrm{C} 2$ & Over time, transfer $10 \%$ of global wealth to an environment fund & 1 & & & 1 & & & \\
\hline D1 & $\$ 10$ trn to move all energy generation to carbon neutral & 1 & 3 & & & 6 & 3 & -3 \\
\hline Al & Sea Levels are rising and flooding is more frequent $\&$ obvious & 0 & & 2 & & 1 & & 2 \\
\hline B1 & Coastal property investments lose money & 0 & & & 1 & & & \\
\hline A4 & Wild Fires are more massive and keep burning down neighbourhoods & -1 & & 4 & 5 & & 2 & \\
\hline B3 & Governments will start being destabilized & -1 & & & & 2 & & \\
\hline $\mathrm{D} 2$ & $\$ 20$ trn to harden the grid and coastal communities & -1 & 1 & & & 5 & & 3 \\
\hline A2 & Hurricanes are getting stronger and more frequent - just look at the news & -2 & & - & 1 & & & \\
\hline A3 & Heat Waves are damaging crops and the food supply & -2 & & 5 & 3 & & 1 & \\
\hline B2 & Children will live in a much lousier world & -2 & 2 & & & 2 & & 1 \\
\hline D3 & $\$ 2$ trn to build a space based sun shade blocking $2 \%$ of sunlight & -4 & & & & 4 & & \\
\hline
\end{tabular}

and keep burning down neighborhoods.) They are critical, but willing to believe in what they see, and in what is promised to them. Table 4 shows the second table of results, elements which drive 'work'. These elements generate positive coefficients when the ratings 4 or 5 were transformed to 100 , and the remaining ratings $(1,2,3)$ were transformed to 0 . Only some elements g ive some sense of a solution, even If not directly a solution. The additive constants show differences in magnitude for complementary groups. Since the scale is 'work' vs. 'not work', the additive constant is the basic belief that a solution will work. The additive constant is higher for males than for females (52 vs. 36 ), higher younger vs. older ( $50 \mathrm{v} 35$ ), and higher for those who worry about themselves versus those who were about others ( 49 vs. 36 ).

The key finding for 'work' is that there some positives on two strong ones. The respondents are not optimistic. There is only one element which is dramatic, however, D4, the plan to spray particulates into the atmosphere to block $2 \%$ of the sunlight. This element or plan performs strongly among males, and among the older respondents, 40 years and older, although in the range of studies conducted previously, coefficients of 8-10 are statistically significant but not dramatic, especially when they belong to only one element. Our third group model concerns the response time associated with each element. The Mind Genomics program measured the total time between the presentation of the vignette and the response to the vignette. Response times of 8 seconds or longer were truncated to the value 8 . OLS regression was applied to the data of the self-defined subgroups. The form of the equation for OLS regression was: Response Time $=\mathrm{k}_{1}(\mathrm{~A} 1)$ $\left.+k_{2}(A 2) \ldots k_{16} D 4\right)$. The key difference moving from binary rating to response time is the removal of the additive constant. The rationale is that we want to see the number of seconds ascribed to each element, for each group. The longer response times mean that the element is more engaging. Table 5 shows the response times for the total panel, the genders, ages, and the two groups defined by what they say worries them. Table 3 shows only those time coefficients of 1.1 second or more, response times or engagement times that are deemed to be relevant and capture the attention. The strongly engaging elements are shown in the shaded cells.

Table 5 suggests that the description of building something can be engage all groups

\section{$\$ 10$ trn to move all energy generation to carbon neutral}

\section{\$20trn to harden the grid and coastal communities}

Women alone are strongly engaged when a clear picture is painted, a picture at the personal level:

\section{Coastal property investments lose money}

\section{Children will live in a much lousier world}

\section{Governments will start being destabilized.}

One of the key features of Mind Genomics is its proposal that in every aspect of daily living people vary $r$ in the way they respond to information. These different ways emerge from studies of granular behavior or attitudes, as well as from studies of macro-behavior or attitudes. Traditional segment-seeking research looks for mindsets in the population, trying to find them by knowing their geodemographics. Both the traditional way of segmentation and the traditional efforts to find these segments in the population end up being rather blunt instruments. The traditional segmentation begins at a high level, encompassing a wide variety of different issues pertaining to the climate, the future, and so forth. The likelihood is minimal of finding the mind-sets with the clear granularity of these mind-sets is 
Table 5: Response times of 1.1second or longer for each element by key self-defined subgroups.

\begin{tabular}{|c|c|c|c|c|c|c|c|c|}
\hline & Response Time (Engagement) & Total & Male & Female & A $18-39$ & A 40+ & Q3 - Inside & Q3 - Outside \\
\hline $\mathrm{D} 4$ & $\$ 0.02 \operatorname{trn}$ to spray particulate into atmosphere to block $2 \%$ of sunlight. & 1.3 & & 1.8 & 1.3 & 1.4 & 1.3 & 1.2 \\
\hline D2 & $\$ 20$ trn to harden the grid and coastal communities & 1.2 & 1.1 & 1.3 & 1.3 & 1.1 & 1.2 & 1.1 \\
\hline B2 & Children will live in a much lousier world & 1.1 & & 1.6 & 1.3 & & & 1.2 \\
\hline D1 & $\$ 10$ trn to move all energy generation to carbon neutral & 1.1 & & 1.2 & & 1.2 & 1.2 & \\
\hline B1 & Coastal property investments lose money & 1.0 & & 1.6 & 1.1 & & & 1.1 \\
\hline B3 & Governments will start being destabilized & 0.9 & & 1.4 & & & & \\
\hline B4 & People will turn from optimistic to pessimistic & 0.9 & & 1.2 & & & & \\
\hline $\mathrm{C} 2$ & Over time, transfer $10 \%$ of global wealth to an environment fund & 0.9 & & & & & 1.1 & \\
\hline A4 & Wild Fires are more massive and keep burning down neighborhoods & 0.9 & & & & & & \\
\hline C3 & Create a unified global climate technology consortium for technological change. & 0.8 & & 1.1 & & & & \\
\hline $\mathrm{C} 4$ & Build a solar shade that blocks $2 \%$ of sunlight & 0.8 & & & & & & \\
\hline $\mathrm{C} 1$ & Right now.. implement a global carbon tax & 0.8 & & & & & & \\
\hline D3 & $\$ 2 \operatorname{trn}$ to build a space based sun shade blocking $2 \%$ of sunlight. & 0.8 & & & & & & \\
\hline A1 & Sea Levels are rising and flooding is more frequent \& obvious & 0.8 & & & & & & \\
\hline A3 & Heat Waves are damaging crops and the food supply & 0.8 & & & & & & \\
\hline A2 & Hurricanes are getting stronger and more frequent - just look at the news & 0.6 & & & & & & \\
\hline
\end{tabular}

low, simply because in the larger scale studies there is no room for the granular, as there is in Mind Genomics, such as this study which deals with 16 elements of stability and destabilization.

Mind Genomics uses a simple k-means clustering divide individuals based upon the pattern of coefficients. The experimental design used in permuted form for each respondent allows the researcher to apply OLS regression to the binary-transformed data of each respondent. The k-means clustering was applied separately to the 55 models for Believe, and separately once again to the 55 models for Work. Both clustering programs came out with similar patterns, two mind-sets for each. The pattern suggested one be called 'Investment focus' and the other be called alarmist focus. The strongest performing elements from this study come from the mind-sets, classifying the respondent by the way the respondent 'thinks' about the topic, rather than how the respondent 'classifies' herself or himself, whether gender, age, or even self-chosen topic of major concern. The mind-sets are named for the strongest performing element. Group 1 (Believe MS-1, Work MS4) show elements which suggest an 'investment focus'. Group 2 (Believe MS2, Work MS3) shows elements which suggest an alarmist focus.

Table 6 shows the strong performing elements for the four mindsets, as well as the most engaging elements for the mind-sets. The reader can get a quick sense of the nature of the mind-sets, both in terms of what they think (coefficients for Believe and for Work, respectively), as well as what occupies their attention and engages them (Response Time) [14].

The mind-sets emerging from Mind Genomics studies do not distribute in the simple fashion that one might expect, based upon today's culture of Big Data. That is, just knowing WHO a person is does not tell us how a person THINKS. The reality is that there are no simple cross-tabulations or even more complex tabulations which directly assign a person to a mind-set. Topics such as the environment, for example, may have dozens of different facets. Knowing the mind of a person regarding one facet, one specific topic, does not necessarily tell us about the mind of that same person with respect to a different, but related facet. Table 7 gives a sense of the complexity of the distribution, and the probable difficulty of finding these mind-sets in the population based upon simple classifications of WHO is a person is.

During the past four years authors Gere and Moskowitz have developed a tool to assign new people to the mind-sets. The tool, called the PVI, the personal viewpoint identifier, uses the summary data from the different mind-sets, perturbing these summary data with noise (random variability), and creating a decision tree based upon a Monte Carlo simulation. The decade PVI allows for 64 patterns of responses of six questions answered on a 2-point. The Monte simulation combined with the decision tree returns with a system to identify mind-set member in $15-20$ seconds. Figure 2 shows a screen shot of the PVI for this study, comprising the introduction, the additional background information stored for the respondent (option), and the six questions, patterns of answers to which assign the respondent immediately to the of the two mind-sets.

\section{Discussion and Conclusion}

The study described here has been presented in the spirit of an exploration, a cartography, a way to understand a problem without having to invoke the ritual of hypothesis. In most study of the everyday life the reality is that the focus should be on what is happening, not on presenting a hypothesis simply for the sake of conforming to a scientific approach which is many cases is simply not appropriate. The issue of climate change is an important one, as a perusal of the news of the day will reveal on just about any day. The issues about the weather, climate change, and the very changes in 'mother earth' are real, political, scientific, and challenge all people. Mind Genomics 
Table 6: Strong performing coefficients for the two groups of emergent mind-sets after clustering on responses (Part 1), and after clustering on response time, viz., engagement (Part 2).

\begin{tabular}{|c|c|c|c|c|c|}
\hline & & \multicolumn{2}{|c|}{ Group 1 Investment focus } & \multicolumn{2}{|c|}{ Group 2 Alarmist focus } \\
\hline \multicolumn{6}{|c|}{ Part 1 -Coefficients for Believe and Work, from the four mind-sets, grouped into two groups } \\
\hline & & \multicolumn{2}{|c|}{ Investors } & \multicolumn{2}{|c|}{ Alarmists } \\
\hline & & Believe MS1 & Work MS2 & Believe MS2 & Work MS1 \\
\hline & & 51 & 46 & 42 & 40 \\
\hline & Focus on investment to solve the problem & & & & \\
\hline D2 & $\$ 20$ trn to harden the grid and coastal communities & 13 & 9 & & \\
\hline D1 & $\$ 10$ trn to move all energy generation to carbon neutral & 9 & 9 & & \\
\hline D3 & $\$ 2 \operatorname{trn}$ to build a space based sun shade blocking $2 \%$ of sunlight. & 8 & 9 & & \\
\hline \multirow[t]{2}{*}{ D4 } & $\$ 0.02 \operatorname{trn}$ to spray particulate into atmosphere to block $2 \%$ of sunlight. & 6 & 8 & & \\
\hline & Focus on alarmist news & & & & \\
\hline A3 & Heat Waves are damaging crops and the food supply & & & 16 & 8 \\
\hline A2 & Hurricanes are getting stronger and more frequent - just look at the news & & & 15 & 11 \\
\hline Al & Sea Levels are rising and flooding is more frequent $\&$ obvious & & & 13 & 10 \\
\hline $\mathrm{C} 1$ & Right now.. implement a global carbon tax & & & & 11 \\
\hline $\mathrm{C} 4$ & Build a solar shade that blocks $2 \%$ of sunlight & & & & 9 \\
\hline \multicolumn{6}{|c|}{ Part 2-Coefficients for Response Time, from the four mind-sets, groups into two groups } \\
\hline & Response time (engagement time) in seconds for an element & Believe MS1 & Wok MS2 & Believe MS & Work MS \\
\hline & Focus on investment to solve the problem & & & & \\
\hline $\mathrm{D} 2$ & $\$ 20$ trn to harden the grid and coastal communities & 1.3 & 1.3 & & \\
\hline D4 & $\$ 0.02$ trn to spray particulate into atmosphere to block $2 \%$ of sunlight. & 1.2 & 1.3 & & \\
\hline B2 & Children will live in a much lousier world & & 1.3 & & \\
\hline D1 & $\$ 10$ trn to move all energy generation to carbon neutral & 1.2 & & & \\
\hline \multirow[t]{2}{*}{ B3 } & Governments will start being destabilized & & 1.1 & & \\
\hline & Focus on alarmist news & & & & \\
\hline D4 & $\$ 0.02 \operatorname{trn}$ to spray particulate into atmosphere to block $2 \%$ of sunlight. & & & 1.4 & 1.3 \\
\hline B4 & People will turn from optimistic to pessimistic & & & 1.4 & 1.3 \\
\hline B2 & Children will live in a much lousier world & & & 1.3 & \\
\hline B3 & Governments will start being destabilized & & & 1.2 & \\
\hline D1 & $\$ 10$ trn to move all energy generation to carbon neutral & & & & 1.2 \\
\hline $\mathrm{D} 2$ & \$20trn to harden the grid and coastal communities & & & 1.1 & 1.1 \\
\hline
\end{tabular}

does not deal with the science of weather, but rather the mind of the individual, doing so by experiments in communication. It is through these experiments, simple to do, easy to interpret, that we begin to understand the nature of people, an understanding which should not, however, surprise. The notion of investors and alarmists makes intuitive sense. These are not the only mind-sets, but they emerge clearly from one limited experiment, one limited cartography. One could only imagine the depth of understanding of people as they confront the changes in the weather and indeed in 'mother earth.' Mind Genomics will not solve those problems, but Mind Genomics will allow the problems to be discussed in a way sensitive to the predispositions of the listener, whether in this case the listener be a person interested in investment to solve the problem or the person be interested in the hue and the cry of the alarmist. Both are valid ways of listening, and for effective communication the messages directed towards each should be tailored to the predisposition of the listener's mind. Thus, a Mind Genomics approach to the problem presents both understanding and suggestion for actionable solution, or at least the messages surrounding that actionable solution [2,15-19].
Table 7: Distribution of key mind-sets (Investors, Alarmists).

\begin{tabular}{|l|c|c|c|c|c|}
\hline & Total & $\begin{array}{c}\text { Investor } \\
\text { (Belief) }\end{array}$ & $\begin{array}{c}\text { Investor } \\
\text { (Work) }\end{array}$ & $\begin{array}{c}\text { Alarmist } \\
\text { (Belief) }\end{array}$ & $\begin{array}{c}\text { Alarmist } \\
\text { (Work) }\end{array}$ \\
\hline Total & 56 & 30 & 24 & 26 & 32 \\
\hline Male & 27 & 15 & 12 & 12 & 15 \\
\hline Female & 29 & 15 & 12 & 14 & 17 \\
\hline Age24-39 & 31 & 14 & 12 & 17 & 19 \\
\hline Age40+ & 25 & 16 & 12 & 9 & 13 \\
\hline Worry about family & 23 & 12 & 8 & 11 & 15 \\
\hline Worry about climate & 12 & 8 & 4 & 4 & 8 \\
\hline Worry about government & 11 & 7 & 6 & 4 & 5 \\
\hline Worry about business & 10 & 3 & 6 & 7 & 4 \\
\hline Worry Other (business and climate) & 21 & 10 & 12 & 11 & 9 \\
\hline Worry Self (Family, Government) & 35 & 20 & 12 & 15 & 23 \\
\hline Invest from Believe & 30 & 30 & 11 & 0 & 19 \\
\hline Invest from Work & 24 & 11 & 24 & 13 & 0 \\
\hline Alarm from Work & 32 & 19 & 0 & 13 & 32 \\
\hline Alarm from Believe & 26 & 0 & 13 & 26 & 13 \\
\hline
\end{tabular}




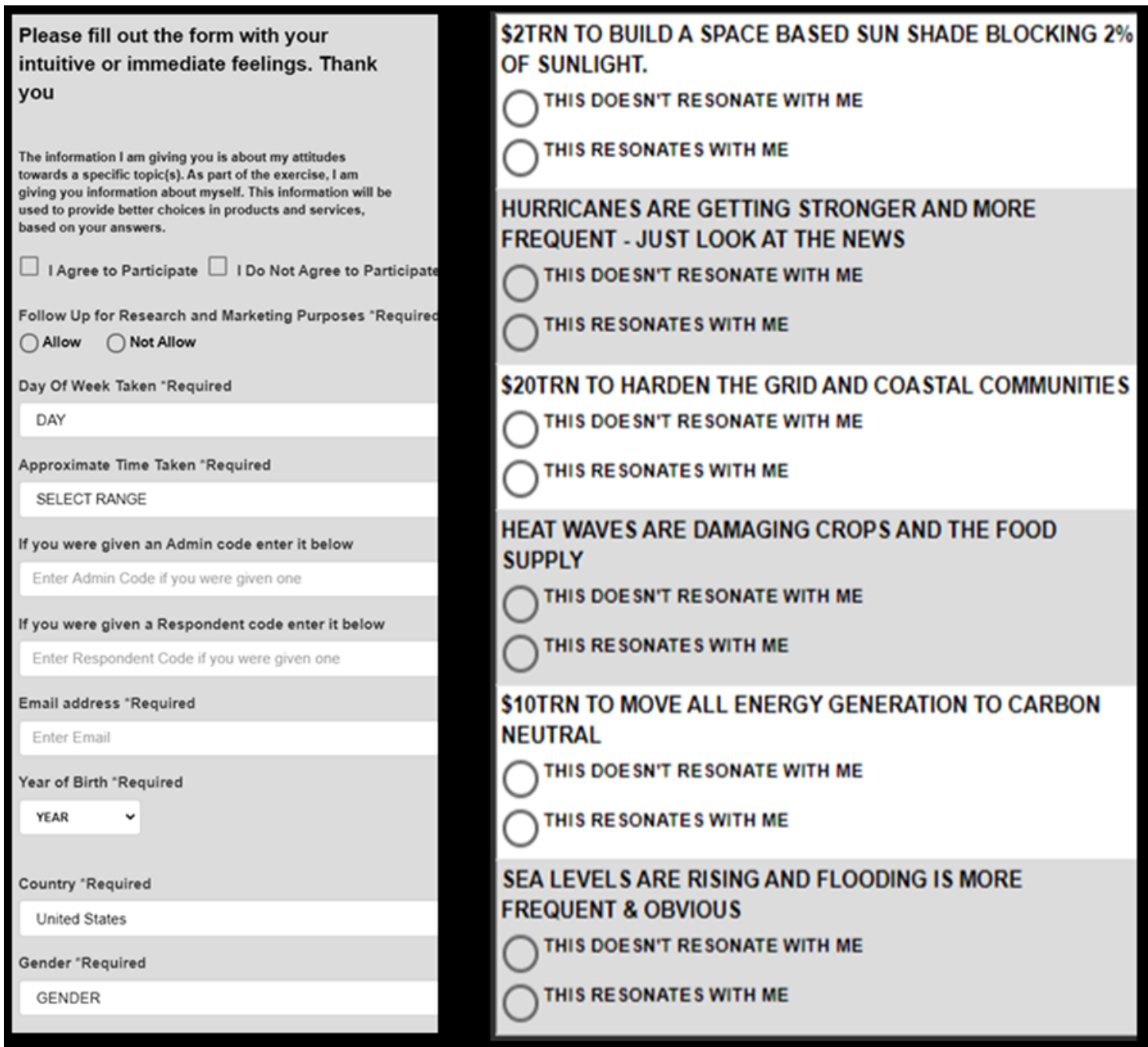

Figure 2: The PVI for the study.

As a final note this paper introduces a novel way to understand the respondent's mind on two dimensions, not just one. The typical Likert Scale presents the respondent with a set of graded choices, from none to a low, disagree to agree, and so forth. The Likert Scale for the typical study is uni-dimensional. Yet, there are often several response dimensions of interest. This study features two response dimensions, belief in the message, and belief that the solution will work. These response dimensions may or may not be intertwined. Other examples might be belief vs. action (would buy). By using a response scale comprising two dimensions, rather than one, it becomes possible to more profoundly understand the way a person thinks, considering the data from two aspects. The first is the message presented, the stimulus. The second is the decisions of the respondent, to select none, one, or both responses, belief in the problem and/or, belief that the solution will work

\section{Acknowledgement}

Attila Gere thanks the support of Premium Postdoctoral Research Program.

\section{References}

1. Tobler C, Visschers VH, Siegrist M (2012) Addressing climate change: Determinants of consumers' willingness to act and to support policy measures. Journal of Environmental Psychology 32: 197-207.

2. Creutzig F, Fernandez B, Haberl H, Khosla R, Mulugetta Y, et al. (2016) Beyond technology: demand-side solutions for climate change mitigation. Annual Review of Environment and Resources 41: 173-198.

3. Lidskog R, Berg M, Gustafsson KM, Löfmarck E (2020) Cold Science Meets Hot Weather: Environmental Threats, Emotional Messages and Scientific Storytelling. Media and Communication 1: 118-128.

4. Nyilasy G, Reid LN (2007) The academician-practitioner gap in advertising. International Journal of Advertising 26: 425-445.

5. Reyes A (2011) Strategies of legitimization in political discourse: From words to actions. Discourse \& Society 22: 781-807.

6. Taleb NN (2007) The black swan: The impact of the highly improbable, Random house, Vol: 2 .

7. Moskowitz HR (2012) 'Mind genomics': The experimental, inductive science of the ordinary, and its application to aspects of food and feeding. Physiology \& Behavior 107: 606-613.

8. Moskowitz HR, Gofman A, Beckley J, Ashman H (2006) Founding a new science: Mind Genomics. Journal of Sensory Studies 21: 266-307. 
9. Moskowitz HR, Gofman A (2007) Selling blue elephants: How to make great products that people want before they even know they want them. Pearson Education.

10. Kahneman D (2011) Thinking, fast and slow. Macmillan.

11. Box GE, Hunter WH, Hunter S (1978) Statistics for Experimenters, New York: John Wiley Vol: 664 .

12. Gofman A, Moskowitz H (2010) Isomorphic permuted experimental designs and their application in conjoint analysis. Journal of Sensory Studies 25: 127-145.

13. Jain AK, Dubes RC (1988) Algorithms for Clustering Data. Prentice-Hall, Inc.

14. Schweickert R (1999) Response time distributions: Some simple effects of factors selectively influencing mental processes. Psychonomic Bulletin \& Review 6: 269-288.
15. Acosta Lilibeth A, Nelson H Enano Jr, Damasa B Magcale-Macandog, Kathreena G Engay, Maria Noriza Q Herrera, et al. (2013) How sustainable is bioenergy production in the Philippines? A conjoint analysis of knowledge and opinions of people with different typologies. Applied Energy 102: 241-253.

16. Lomborg B (2010) Smart solutions to climate change: Comparing costs and benefits. Cambridge University Press.

17. Nerlich B, Koteyko N, Brown B (2010) Theory and language of climate change communication. Wiley Interdisciplinary Reviews: Climate Change 1: 97-110.

18. Tol RS (2009) The economic effects of climate change. Journal of Economic Perspectives 23: 29-51.

19. Warren $\mathrm{R}$ (2011) The role of interactions in a world implementing adaptation and mitigation solutions to climate change. Philosophical Transactions of the Royal Society A: Mathematical, Physical and Engineering Sciences 369: 217-241.

\section{Citation:}

Moskowitz H, Yaschin A, Harizi A, Davidov S, Deitel P, et al. (2020) Thinking Climate - A Mind Genomics Cartography.. Environ Sustain Clim Change Volume 2(1): $1-11$. 